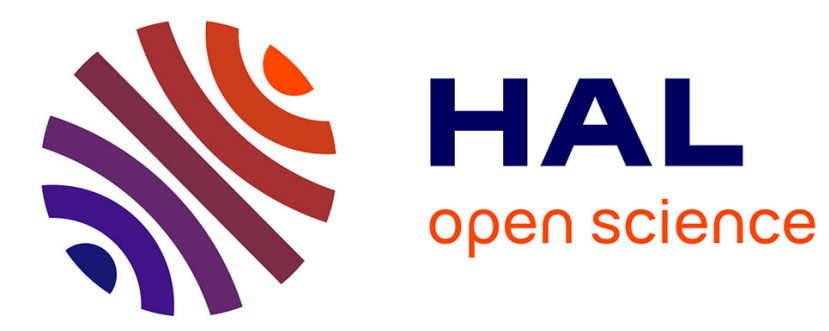

\title{
On the formation of propylene oxide from propylene in space: gas-phase reactions
}

\author{
Enrico Bodo, Giulia Bovolenta, Chloe Simha, Riccardo Spezia
}

\section{To cite this version:}

Enrico Bodo, Giulia Bovolenta, Chloe Simha, Riccardo Spezia. On the formation of propylene oxide from propylene in space: gas-phase reactions. Theoretical Chemistry Accounts: Theory, Computation, and Modeling, 2019, 138 (8), pp.97. 10.1007/s00214-019-2485-3 . hal-02276441

\section{HAL Id: hal-02276441 \\ https://hal.science/hal-02276441}

Submitted on 14 Oct 2020

HAL is a multi-disciplinary open access archive for the deposit and dissemination of scientific research documents, whether they are published or not. The documents may come from teaching and research institutions in France or abroad, or from public or private research centers.
L'archive ouverte pluridisciplinaire $\mathbf{H A L}$, est destinée au dépôt et à la diffusion de documents scientifiques de niveau recherche, publiés ou non, émanant des établissements d'enseignement et de recherche français ou étrangers, des laboratoires publics ou privés. 


\title{
On the formation of propylene oxide from propylene in space: gas phase reactions.
}

\author{
Enrico Bodo · Giulia Bovolenta • Chloe \\ Simha · Riccardo Spezia
}

the date of receipt and acceptance should be inserted later

\begin{abstract}
In the present article we have investigated the possibility of forming propylene oxide (PO) from propylene (PE) by bi-molecular reactions. Propylene oxide is the first chiral molecule observed in the interstellar medium, and studying the thermodynamics and kinetics of formation can suggest possible synthetic routes. We have focused our attention on gas phase reactions, and the presence of an environment is discussed in particular for the possibility of forming it by association reactions. In particular, we have considered radical and ion-molecule reactions. Results show that the main gas-phase route to PO formation is represented by ion-molecule reactions which turn out to be compatible with astrophysical conditions, notably: $\mathrm{PE}+\mathrm{O}^{+}$and $\mathrm{PE}+\mathrm{HO}_{2}^{+}$. Their final product is not $\mathrm{PO}$, but its ionized variant $\mathrm{PO}^{+}$that can be neutralized by electron capture. The only thermodynamically and kinetically allowed reaction which can directly lead to neutral $\mathrm{PO}$ is a collision of $\mathrm{PE}$ with a singlet-excited $\mathrm{OH}^{+}$but two competing reactions (leading to $\mathrm{PE}^{+}$and $\mathrm{PO}^{+}$) are thermodynamically favored and thus more plausible in space.
\end{abstract}

\section{Introduction}

In last years, thanks to the rapid development of radio-telescopes and space missions, the number of complex organic molecules (COMs) detected in space has

\section{E. Bodo*}

Department of Chemistry, University of Rome "La Sapienza", Italy E-mail: enrico.bodo@uniroma1.it

G. Bovolenta

Department of Chemistry, University of Rome "La Sapienza", Italy

C. Simha

Laboratoire de Chimie Théorique, LCT, CNRS, Sorbonne Université, 4, Place Jussieu, 75252 Paris Cedex 05, France

R. Spezia*

Laboratoire de Chimie Théorique, LCT, CNRS, Sorbonne Université, 4, Place Jussieu, 75252

Paris Cedex 05, France E-mail: riccardo.spezia@sorbonne-universite.fr 
been an incredible growth. In particular, the interstellar medium (ISM) was found to be populated of different organic molecules, like for example propylene [1], formamide [2], cyanic or isocianic acids [3,4]. Restraining to ISM, seven new molecules were reported in 2017 and six in 2018 and in first months of 2019 already two new COMs (Z-cyanomethanimine [5] and glycolonitrile [6]) have been added to the family of known astromolecules, showing how the complexity of species present in the ISM is not limited to simple and elementary atoms or diatomics. Recently, the propylene oxide $\left(\mathrm{C}_{3} \mathrm{H}_{6} \mathrm{O}\right)$ was detected in Sagittarius B2 [7] and it is a particularly intriguing molecule since it was the first chiral molecule ever detected. Although its enantiomeric composition was not measured, its presence in the ISM can let us surmise that a reservoir of chiral molecules exists and that it is formed outside the earth, being a possible grain for further chiral discrimination in the universe.

While many molecules were detected, much less is known on how they were formed. Generally, two classes of source are discussed and considered: (i) formation by gas phase reactions; (ii) formation in the interstellar grains. While in last years some experimental evidences have shown that some molecules can be formed on icy grains under conditions which mimic reasonable astrophysical ones, [8-12] the possibility of gas-phase reactions as responsible of their origin cannot be excluded even for complex molecules. [13-15]

The fundamental problem at the basis of the synthesis of such molecules is that the ISM is characterized by very low temperatures (in $10-70 \mathrm{~K}$ range) and densities $\left(10^{4}-10^{6}\right.$ molecules per cubic centimeter in densest nebulae). [16,17] This is at the origin of two aspects which must be taken into account when proposing synthetic pathways. First, the reactions must be exothermic and without an activation barrier (or a very low one), since temperature strongly limits the kinetic energies required to overcome reaction barriers $(10 \mathrm{~K}$ and $70 \mathrm{~K}$ will correspond to 0.02 and $0.1 \mathrm{kcal} / \mathrm{mol}$, respectively). Secondly, in the case of bi-molecular associations (e.g. reactions like $\mathrm{A}+\mathrm{B} \rightarrow \mathrm{C}$ ) the system must have a way to dissipate its energy before dissociating back to reactants. Two processes can stabilize the associated species: collisional deactivation and/or spontaneous emission of a photon (radiative association). [14,18] These two processes are in competition with the unimolecular fragmentation, which has, by definition, enough energy to occur. Under extreme vacuum conditions the first process is not likely to occur, therefore, only radiative association is possible. The rate of radiative association depends on different factors (number of atoms, dipole moment, density of vibrational states), but for molecules of about 10 atoms in size it turns out very likely to be slower than unimolecular dissociation, [19] as we have estimated recently for urea. [20] In other words, the most efficient route for forming a molecule out of a binary collision, is a reactive scattering processes ( such as $\mathrm{A}+\mathrm{B} \rightarrow \mathrm{C}+\mathrm{D}$ ) where the excess energy due to the formation of the more stable products can be converted into translational energy. Clearly, if the density of the environment is high enough, the direct association $\mathrm{A}+\mathrm{B} \rightarrow \mathrm{C}$ becomes a competitive route of formation of the specie $\mathrm{C}$ because its internal energy can be dissipated by interacting with nearby atoms/molecules: in this case the process overall rate is characterized by its collisional rate with the environment. [14]

Using theoretical chemistry methods represents a powerful approach to understand the various formation/depletion channels of relatively complex molecular species, both in the gas phase and on the grain surfaces. Such approach has been applied to investigate possible reaction pathways for the synthesis of 
Table 1 Column densities of species considered in this study

\begin{tabular}{l|c|r} 
Species & Column density $\left(\mathrm{cm}^{-2}\right)$ & Reference \\
\hline $\mathrm{PE}$ & $4 \cdot 10^{13}$ & Marcelino et al. [1] \\
$\mathrm{O}\left({ }^{3} \mathrm{P}\right)$ & $>10^{15}$ & Glassgold and Langer [37] \\
& & Hollenbach et al. [38] \\
$\mathrm{OH}$ & $1.7-3.9 \cdot 10^{14}$ & Wiesemeyer et al. [39] \\
$\mathrm{OH}^{+}$ & $2.6 \cdot 10^{14}$ & Wyrowski et al. [40] \\
$\mathrm{HO}_{2}$ & $2.8 \cdot 10^{12}$ & Parise et al. [41] \\
$\mathrm{HO}_{2}^{+}$ & $\sim 10^{9}$ & Widicus Weaver et al. [42] \\
$\mathrm{PO}$ & $3.0-6.7 \cdot 10^{14}$ & Cunningham et al. [43]
\end{tabular}

$\mathrm{PE}=$ propylene; $\mathrm{PO}=$ propylene oxide; $\mathrm{HO}_{2}^{+}$was not directly detected, the abundance reported is an estimation.

different COMs, [21] like e.g. formamide, [22-25] methanol, [26] acetamide, [23] urea, [20] formaldehyde, [27,26] acetone, [27] acetaldehyde [27,28], glycolaldehyde, [29] acetic acid [29], methyl formate [30], hydroxyacetonitrile [31], formic acid [29] or glycine. [11,32,33,28] Here we focus on the possibility of obtaining propylene oxide by gas phase ion-molecule or radical reactions. Note that more recently it was shown that supplementary insights can be obtained by chemical dynamics [34-36]: these methods need information obtained from the study of thermodynamics and energy barriers which can be obtained accurately only from highly-correlated quantum chemistry calculations.

By inspecting the astromolecule list one can notice that propylene was also been observed, with a relatively high abundance [1]. This can be reasonably thought as a viable precursor of propylene oxide. We have thus considered the possible reactions between propylene and other simple molecular species with relatively high abundances, such as: $\mathrm{O}, \mathrm{OH}, \mathrm{OH}^{+}, \mathrm{HO}_{2}, \mathrm{HO}_{2}^{+}$. Column densities of the considered species are reported in Table 1 with corresponding references. We have also considered the possibility of reaction with $\mathrm{O}^{+}$which is likely to be formed in the ISM by the simple reaction: [37]

$$
\mathrm{H}^{+}+\mathrm{O} \rightarrow \mathrm{H}+\mathrm{O}^{+}
$$

In particular, we focused on both radical-neutral and ion-neutral reactions, given that the latter reactions generally have a very low activation energy due to the attractive ion-dipole potentials. However, radical-neutral reactions were found recently to be a possible route to synthesize COMs in the gas phase, as for formamide glycolaldehyde, acetic acid and formic acid [24,29]. In the present work, we studied reaction thermodynamics and kinetics in the gas phase by means of quantum chemistry calculations, providing insights of elementary reactions in absence of any environment, so focusing on intrinsic properties.

\section{Computational Details}

All calculations have been performed using Gaussian16 [44] and Orca. [45] Isolated ground state molecules partaking to the various reactions have been geometryoptimized using the following methods: B3LYP/cc-pVTZ [46, 47], B2PLYP-D3/augcc-pVTZ [48,49], MP2/aug-cc-pVTZ [50] and PBEh-3c [51] where the respective 
unrestricted schemes were used for open shell species. Singlet, open-shell intermediates have been computed using the unrestricted, broken symmetry formalism. The molecular energy at the CCSD(T)/aug-cc-pVTZ [52] has then been evaluated using the MP2 geometries. B3LYP was used because it is well known to provide reasonable geometries, MP2 and $\operatorname{CCSD}(\mathrm{T})$ are somehow the standard in astrochemistry, $[22,23,20]$ and B2PLYP-D3 gives excellent thermodynamics and was used recently by Skouteris et al. in astrochemical related radical reactions. [29]

In order to investigate the reaction paths and to evaluate the possible presence of barriers along them, we have also performed many different scans of the internal coordinates. Generally these scans are obtained by imposing a constrain on one coordinate and optimizing all the others (relaxed PES scan). Since the optimizations have to be repeated for very many different geometries and in order to make our computation efficient, we have adopted two different simplified schemes for the relaxed scans. For the radical reactions, we have performed the entire computations with the B3LYP/cc-pVTZ method. For the ionic reactions, where the energy differences are much larger, we have employed the PBEh-3c method for an even more efficient evaluation. The thermodynamic reliability of the PBEh-3c method, for the molecules under study, can be seen by looking at the data reported in Table 2 where it performs almost like the much more expensive B2PLYP-D3 approach.

\section{Results}

\subsection{Thermodynamics}

In order to model the formation of the PO molecule, we have taken into considerations reactions that involve its obvious precursor that is PE. As possible reactive partners we have obviously taken into consideration several oxygen containing species that have a sizable abundance in the ISM. Among the possible oxygen bearing molecules we have only considered radicals and ions since neutral closed shell species do present high activation barriers towards the double bond addition. This means that we have not considered reactions with water or CO which are ubiquitous and abundant components of the ISM. For example, a set of preliminar computations has shown that the gas phase addiction of water to the double bond of PE shows a barrier of more than $60 \mathrm{kcal} / \mathrm{mol}$. Our selection of oxygen bearing molecules, thus, includes the $\mathrm{O}, \mathrm{OH}$ and $\mathrm{OOH}$ radicals and their respective positive ions. Ions such as $\mathrm{CO}^{+}$and $\mathrm{H}_{2} \mathrm{O}^{+}$have also been considered, but preliminary calculations have shown the reaction to be nearly impossible because the former has a very high dissociation energy while the latter presents an unfavorable reaction mechanism given that $\mathrm{H}_{2}^{+}$has to be eliminated after oxygen addiction.

Table 2 reports the energy difference with zero-point vibrational energy (ZPE) corrections between products and reactants of the various possible routes we have considered for PO formation. The two reactions $\mathbf{1}$ and $\mathbf{4}$ are two exothermic association processes. Actually the first one is the well known reaction of oxygen addiction to an olefin. In the context of astrochemistry, these two routes are likely to occur either within a high density environments where frequent collisions processes can remove the excess energy from the molecular complex or by radiative association. Reaction $\mathbf{2}$ is an endothermic neutral-radical process which involves 
Table 2 Energies of reactions (different methods) including ZPE in $\mathrm{kcal} / \mathrm{mol} .^{a}$

\begin{tabular}{|c|c|c|c|c|c|c|}
\hline & & PBEh-3c & B3LYP & B2PLYP & MP2 & $\operatorname{CCSD}(\mathrm{T})^{b}$ \\
\hline \multicolumn{7}{|c|}{ Radicalic reactions } \\
\hline 1 & $\mathrm{PE}+\mathrm{O}\left({ }^{3} \mathrm{P}\right) \rightarrow \mathrm{PO}$ & -80.8 & -79.8 & -83.8 & -92.3 & -82.3 \\
\hline 2 & $\mathrm{PE}+\mathrm{OH}\left({ }^{2} \Sigma\right) \rightarrow \mathrm{PO}+\mathrm{H}\left({ }^{1} S\right)$ & +13.8 & +19.3 & +17.3 & +7.2 & +16.9 \\
\hline 3 & $\left.\mathrm{PE}+\mathrm{HO}_{2}\left({ }^{2} A^{\prime}\right) \rightarrow \mathrm{PO}+\mathrm{OH}^{2} \Sigma\right)$ & -21.8 & -17.0 & -19.6 & -28.8 & -22.1 \\
\hline \multicolumn{7}{|c|}{ Ionic Reactions } \\
\hline 4 & $\mathrm{PE}+\mathrm{O}^{+}\left({ }^{2} P\right) \rightarrow \mathrm{PO}^{+}$ & -264.4 & -264.8 & -261.8 & -259.0 & -240.9 \\
\hline 5 & $\mathrm{PE}+\mathrm{OH}^{+}\left({ }^{1} \Delta\right) \rightarrow \mathrm{PO}^{+}+\mathrm{H}\left({ }^{1} S\right)$ & -124.0 & -121.1 & -119.6 & -118.5 & -103.0 \\
\hline 6 & $\mathrm{PE}+\mathrm{OH}^{+}\left({ }^{1} \Delta\right) \rightarrow \mathrm{PO}+\mathrm{H}^{+}$ & -43.9 & -37.0 & -39.9 & -49.4 & -24.2 \\
\hline 7 & $\mathrm{PE}+\mathrm{HO}_{2}^{+}\left({ }^{1} A\right) \rightarrow \mathrm{PO}^{+}+\mathrm{OH}\left({ }^{2} \Sigma\right)$ & -67.8 & -65.8 & -57.5 & -45.4 & -52.7 \\
\hline \multirow[t]{2}{*}{8} & $\mathrm{PE}+\mathrm{HO}_{2}^{+}\left({ }^{1} A\right) \rightarrow \mathrm{PO}+\mathrm{OH}^{+}\left({ }^{1} \Delta\right)$ & +70.1 & +77.0 & +79.5 & +80.3 & +66.9 \\
\hline & Mean Absolute Error & 10.9 & 11.0 & 9.4 & 13.2 & - \\
\hline
\end{tabular}

$\mathrm{PE}=$ propylene; $\mathrm{PO}=$ propylene oxide.

${ }^{a}$ Basis sets are: cc-pVTZ (B3LYP), aug-cc-pVTZ (B2PLYP-D3, MP2 and CCSD(T)).

${ }^{b} \mathrm{ZPE}$ and geometry were calculated at MP2 level of theory.

the dissociation of the rather stable $\mathrm{OH}$ radical molecule. Reaction 3 requires a collision with the peroxide radical and represents a neutral-radical pathway which is exothermic because it involves the formation of the highly stable $\mathrm{OH}$ radical molecule. Reactions 5-6 are two ion-molecule reactions with the same entrance channel and two possible products. The lowest energy one is an ionized PO that can be further neutralized by electron capture. Reactions 7-8 are ion-molecule reactions which require a collision with an ionized peroxide. As for reactions 4-5, the lowest energy outcome is an ionized PO.

Energetic values are obtained at different levels of theory and, assuming that $\operatorname{CCSD}(\mathrm{T})$ is the most accurate one, we can provide some method comparison. Mean absolute error (MAE) was used to provide an overall evaluation. We can notice that DFT provides better results than MP2. Interestingly, cheaper methods like B3LYP and PBEh-3c perform very well, with results not far from more expensive B2PLYP-D3. The former methods are thus used to perform specific scans in the following studies of reaction pathways.

\subsection{Radicalic Reactions}

Among the radical reactions, only $\mathbf{1}$ and $\mathbf{3}$ have a favorable thermodynamics $(\Delta$ $\mathrm{E}<0)$. Nevertheless, we shall discuss in details all three radical-neutral reactions.

\subsubsection{The $\mathrm{PE}+\mathrm{O}\left({ }^{3} P\right)$ reaction.}

This is an associative reaction which needs a spin crossing from the triplet PES involving $\mathrm{O}\left({ }^{3} \mathrm{P}\right)$ to the final singlet one involving $\mathrm{PO}$. The reaction proceeds by forming a stable compound between the triplet oxygen atom and the PE molecule (we indicate this compound as ${ }^{3}[\mathrm{PE}-\mathrm{O}]$ ) as shown in Scheme 1 . The formation of the triplet adduct leads to a gain of about $25 \mathrm{kcal} / \mathrm{mol} .{ }^{3}[\mathrm{PE}-\mathrm{O}]$ is a triplet intermediate from which two (singlet) products can be formed by inter-system crossing: (1) the propylene oxide (PO) by a simple "closure" of the 3-member ring, and (2) the propionaldehyde (propanal, PA) which can be formed by hydrogen migration. 


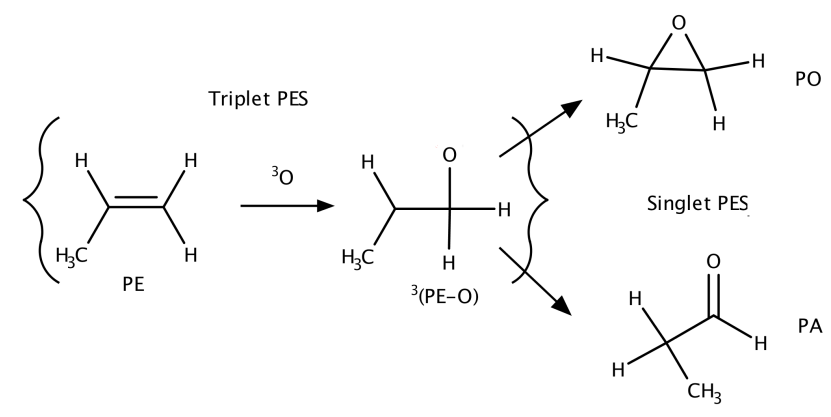

Fig. 1 Triplet oxygen addiction to PE

The inter-system crossing point is actually located very near the stable geometry of the triplet complex where the energy difference between the singlet and triplet state has been found to be only $0.2 \mathrm{kcal}$. To obtain the two products it is necessary a spin transition, from triplet state of the $\mathrm{CH}_{3} \mathrm{CH}-\mathrm{CH}_{2} \mathrm{O}$ intermediate to the singlet state of propylene oxide and propanal. The change in spin multiplicity leads to an intermediate propilene oxide which is a singlet diradical ${ }^{1}[\mathrm{PE}-\mathrm{O}]$. The fate of this singlet diradical toward PO or PA depends upon the value of the dihedral angle around the two carbon atoms that were involved in the double bonds, namely O-C-C-H. For values of this angle larger than 50 degrees the formation of the desired product PO is favored with a final gain of $57 \mathrm{kcal} / \mathrm{mol}$. If the angle is less than 50 degrees the formation of PA is favored with an additional gain of $22 \mathrm{kcal} / \mathrm{mol}$. The energies of the products involved in the reaction are reported in Figure 2.

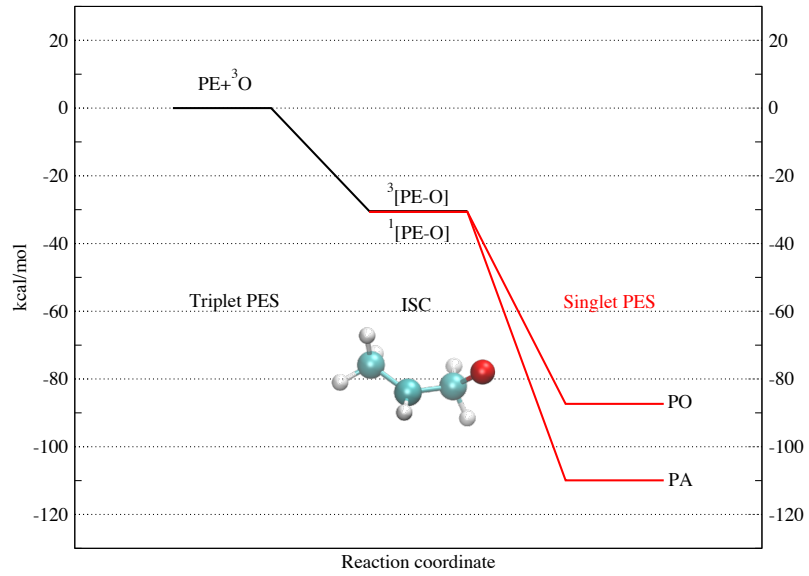

Fig. 2 PES of the reaction $\mathrm{PE}+\left({ }^{3} \mathrm{P}\right) \mathrm{O} \rightarrow \mathrm{PO} / \mathrm{PA}$ as obtained at B3LYP/cc-pVTZ level of theory. The structure of the triplet ${ }^{3}[\mathrm{PE}-\mathrm{O}]$ compound is also shown. 
The fact that the reaction requires an inter-system crossing (generally a slowly occurring process) and that the singlet complex ${ }^{1}[\mathrm{PE}-\mathrm{O}]$ requires an energetic stabilization (either from the environments or by photon emission), makes this reaction a rather unlikely route to $\mathrm{PO}$ formation under astrophysical conditions. Furthermore, PA is more stable than PO and following the so-called "minimum energy principle" in astrochemistry $[53,54]$ PA should be obtained.

\subsubsection{The $\mathrm{PE}+\mathrm{OH}\left({ }^{2} \Sigma\right)$ reaction.}

This reaction is globally endothermic by at least $19 \mathrm{kcal} / \mathrm{mol}$ (see Table 2), therefore almost impossible under astrophysical conditions. At difference with the previous case, the reaction takes place on a single PES of doublet multiplicity without the need to have an inter-system crossing. In addition, the reaction has a barrier along the exit channel due to the high dissociation energy of the $\mathrm{OH}$ bond which has to be broken in order to release $\mathrm{H}$. This "late" transition state is characterized by a structure where the incipient formation of the epoxide is apparent as shown by the structure reported in Figure 3. The energy of this transition state is around $30 \mathrm{kcal} / \mathrm{mol}$ higher than the entrance channel thereby making the collision energy required to for the desired product even larger than the $20 \mathrm{kcal} / \mathrm{mol}$ due to endothermicity.

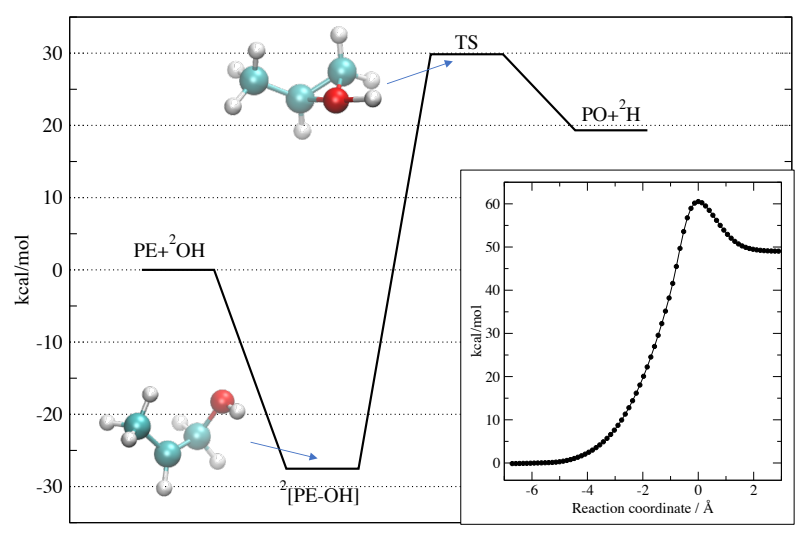

Fig. 3 PES of the reaction $\mathrm{PE}+\left({ }^{2} \Sigma\right) \mathrm{OH} \rightarrow \mathrm{PO}$ as obtained at B3LYP/cc-pVTZ level of theory. The minimum energy path in the exit channel is reported in the inset. The structures of the PE-OH complex and of the transition state in the exit channel are also shown.

\subsubsection{The $\mathrm{PE}+\mathrm{HO}_{2}\left({ }^{2} A^{\prime}\right)$ reaction.}

The global reaction with hydroperoxide radical $(\mathrm{OOH})$ is exothermic and therefore it appears as a possible realistic formation channel of PO. The ground state of $\mathrm{OOH}$ is a doublet and so the reaction to form PO has to proceed on a single PES 
of doublet multiplicity. Although the reaction seems, in principle, quite straightforward, the ground state of $\mathrm{OOH}\left({ }^{2} A^{\prime \prime}\right)$ is not reactive toward the double bond $[55,56]$. This is the consequence of a "wrong" symmetry of the singly occupied molecular orbital that, in the ground state, is perpendicular to the radical plane. An electronic rearrangement of the electrons of $\mathrm{OOH}$ into its first excited configuration $\left({ }^{2} A^{\prime}\right)$, where the singly occupied orbital is in the plane, makes the radical reactive toward to the double bond of $\mathrm{PE}$. The energy required for the electronic rearrangement results in a repulsive interaction between the ground state $\mathrm{OOH}$ $\left({ }^{2} A^{\prime \prime}\right)$ and $\mathrm{PE}$ and hence, in the emergence of a barrier in the entrance channel of the reaction. The ground state potential due to its repulsive shape, crosses the excited ${ }^{2} A^{\prime}$ PES. The crossing point between the ${ }^{2} A^{\prime}$ and ${ }^{2} A^{\prime} 1$ PES's (actually a conical intersection, CI) can be localized around $16 \mathrm{kcal} / \mathrm{mol}$ above the entrance channel as reported in Figure 4 where the entire PES for the relevant reaction is shown. In addition to the first, a second barrier appears on the ground state PES in the exit channel before the formation of PO. The height of this second barrier is about $10 \mathrm{kcal}$ above the ground state entrance channel, but about 6 kcal lower than the excited state one. As a consequence of the above electronic

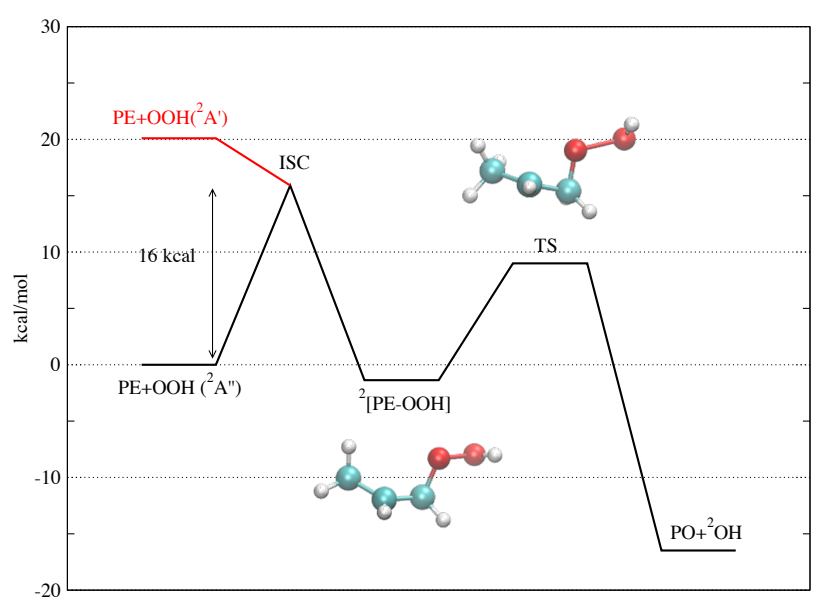

Fig. $4 \mathrm{PES}$ of the reaction $\mathrm{PE}+\mathrm{HO}_{2} \rightarrow \mathrm{PO}+\mathrm{OH}$ as obtained at the UB3LYP/cc-pVTZ level of theory. The excitation energy of the isolated radical on the left has been taken from ref. [57]

structure problem, the reaction with the $\mathrm{OOH}$ radical does not appear as a viable route to the formation of PO in the ISM. The only possibility for this reaction to occur efficiently at low temperature is an electronic excitation (of about $0.9 \mathrm{eV}$, due to visible radiation) of the reactants from the ${ }^{2} A^{\prime \prime}$ to the ${ }^{2} A^{\prime}$ state. For this reason this reaction can be effective only in region of the ISM where a sufficient irradiation occurs. 
3.3 Ion-molecule Reactions

All the ion-molecule reactions, except reaction $\mathbf{8}$ are exothermic thereby representing viable routes of formation of PO in the ISM. As it often happens for ion molecule reactions, and as we shall see in below, these reactions are barrierless and the pathways that leads to product formations are straightforward.

3.3.1 The $\mathrm{PE}+\mathrm{O}^{+}\left({ }^{2} P\right)$ reaction.

Reaction 4 proceeds by association from the reactants to the charged product $\mathrm{PO}^{+}$, without any stable intermediate. In analogy to the reaction with atomic neutral oxygen, this is a typical association process which needs the releasing of the excess energy through collisions or photon emission. After association, the cation should combine with an electron and form the neutral PO, so that the overall process is:

$$
\begin{gathered}
\mathrm{PE}+\mathrm{O}^{+} \rightarrow \mathrm{PO}^{+}+h \nu \\
\mathrm{PO}^{+}+e^{-} \rightarrow \mathrm{PO}
\end{gathered}
$$

Radiative association processes are often inefficient, but their rate tends to increase with the stabilization energy of the complex, the dipole of the system and the number of atoms in the final product (the key factors that determine the density of available final vibrational states [58]). Given that the stabilization energy of the $\mathrm{PO}^{+}$complex exceeds $10 \mathrm{eV}$ and that the complex contain 10 atoms we can estimate the reaction rate to be of the order of $10^{-9} \mathrm{~cm}^{3} \mathrm{~s}^{-1}$ if not larger. This value is larger than what measured, for example, by Gerlich and co-workers [59] for the formation of $\mathrm{C}_{3} \mathrm{HD}^{+}, \mathrm{C}_{3} \mathrm{HD}_{2}^{+}$and $\mathrm{C}_{3} \mathrm{D}_{3}^{+}$and thus radiative association cannot be disregarded as possible formation mechanism. Note that the most stable electronic configuration of $\mathrm{O}^{+}$is a ${ }^{4} S$ (that cannot associate directly with $\mathrm{PE}$ ) therefore the likelihood of this process depends also on the abundance of ${ }^{2} P$ oxygen.

Neutralization of $\mathrm{PO}^{+}$can occur directly by combination with an electron, but also via a charge exchange process with other species present in the ISM. In this case the ionization energy (IE) drives the thermodynamics of the process:

$$
\mathrm{PO}^{+}+\mathrm{A} \rightarrow \mathrm{PO}+\mathrm{A}^{+}
$$

where A must have an IE smaller than that of PO, which is $10.22 \mathrm{eV}$. [60] This is a relatively low value, such that most abundant species in the ISM have higher IE. Between the species considered in the reaction studied here, interestingly only PE has a lower IE $(9.73 \mathrm{eV})$. [60] Radical species observed in the ISM have lower IE, like formyl radical $(8.12 \mathrm{eV})$ [60] or cyanoethynyl radical $(4.3 \mathrm{eV})$. [60] Also hydrocarboxyl radical has a lower IE (8.2 eV) [61] and interestingly only the charged $\mathrm{HOCO}^{+}$species was observed in the ISM. [62]

$$
\text { 3.3.2 The } \mathrm{PE}+\mathrm{OH}^{+}\left({ }^{1} \Delta\right) \text { reaction. }
$$

The reaction with $\mathrm{OH}^{+}\left({ }^{1} \Delta\right)$ is exothermic and produces two possible products depending where the charge is localized in the exit channel. The lowest energy one is the channel $\mathrm{PO}^{+}+\mathrm{OH}$ which corresponds to a globally singlet state made 
by two doublet radicals coming from the homolytic dissociation of the $\mathrm{O}-\mathrm{H}$ bond. The one with higher energy (around $80 \mathrm{kcal} / \mathrm{mol}$ asymptotically) corresponds to $\mathrm{PO}+\mathrm{OH}^{+}$, requiring an heterolytic dissociation of the $\mathrm{O}-\mathrm{H}$ bond. A scheme of the energies involved in the four ionic reaction is reported in the left panel of Figure 5. As it is clear from this figure, the (non-reactive) charge exchange process

$$
\mathrm{PE}+\mathrm{OH}^{+} \rightarrow \mathrm{PE}^{+}+\mathrm{OH}
$$

is a "parasitic" channel with a higher exothermicity, thereby favored by thermodynamics alone. However, the formation of $\mathrm{PO}^{+}$by

$$
\mathrm{PE}+\mathrm{OH}^{+} \rightarrow \mathrm{PO}^{+}+\mathrm{H}
$$

is energetically competitive and might represent a possible product of the reaction depending on the mutual orientation of the two colliding partners.
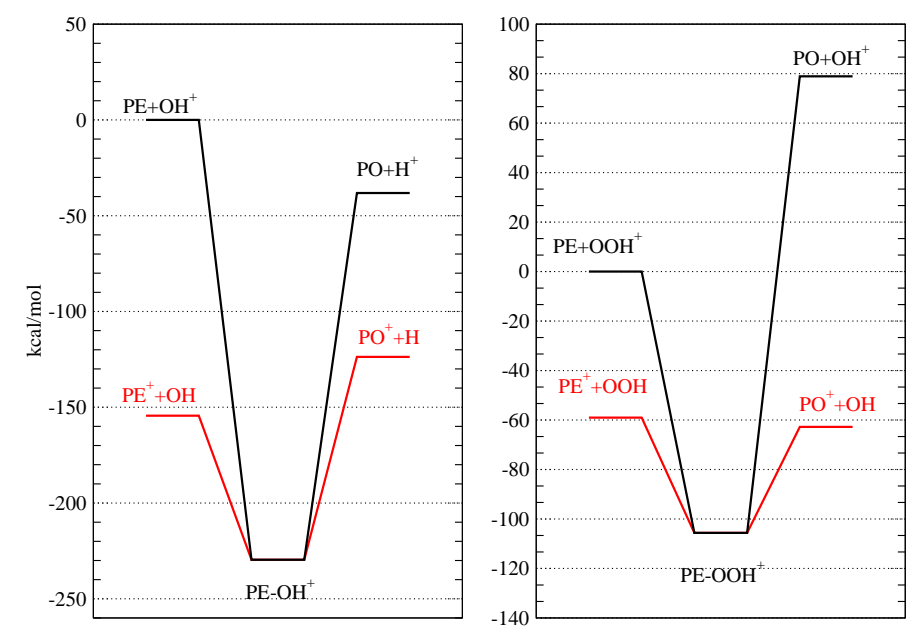

Fig. 5 Ionic reactions: energies of the entrance and exit channels and of the ionic complexes at the PBEh-3c level. ZPE is not included.

In order to explore the pathways bringing the collision to form $\mathrm{PO}^{+}$or $\mathrm{PO}$ and to ensure that no barriers are present, we have decided to perform a scan of the potential energy surface (PES) in the entrance and in the exit channel. First of all, the complex of $\mathrm{PO}$ with $\mathrm{OH}^{+}$has been optimized. Starting from this geometry, a restricted PBEh-3c series of calculation has been performed at different values of the relevant reactive coordinates. At each of the coordinate values the entire geometry of the system has been optimized in order to find the minimum energy path along the PES: to describe the PES in the exit channel we have gradually increased the $\mathrm{O}-\mathrm{H}$ coordinate. The results are reported in the right panel of Figure 6 in black; to describe the entrance channel we have to gradually increase one of 
the C-O distances. Since there are two possible C-O distances we have produced two PESs. An additional constrain (apart from the reactive coordinate) that we had to enforce in order to compute the entrance channel PES was to keep the direction of approach of the $\mathrm{OH}$ molecule along a straight line. Therefore, for both $\mathrm{C}-\mathrm{O}$ distance scans we have also kept fixed the $\mathrm{C}-\mathrm{C}-\mathrm{O}$ angle. The two scans along both $\mathrm{C}-\mathrm{O}$ bonds have produced very similar results and we limit ourselves here to present the results pertaining to the inner carbon atom that are reported in the left panel of Figure 6.

Since a restricted calculation naturally produces an heterolytic bond cleavage, at each of the optimized geometries on the PES, we have performed an additional "broken symmetry" unrestricted calculation to obtain the energy of the homolytic dissociation channel (that is the actual ground state of the system). The two broken symmetry PES for both the entrance and exit channels have been also reported in Figure 6 where the data in red correspond to the homolytic bond cleavage. For short distances the red and black PES are identical and we reported the data only in black color. The reason why the energies do not perfectly match those in Table 2 or in Figure 5 lies in the fact that broken symmetry calculations are only an approximation to the true PESs that should be computed by means of a multiconfigurational scheme and also in the use of angular constraints that alter the true asymptotic energy. Nevertheless these qualitative calculations are sufficient to ensure that there are no barriers along the reaction coordinates.
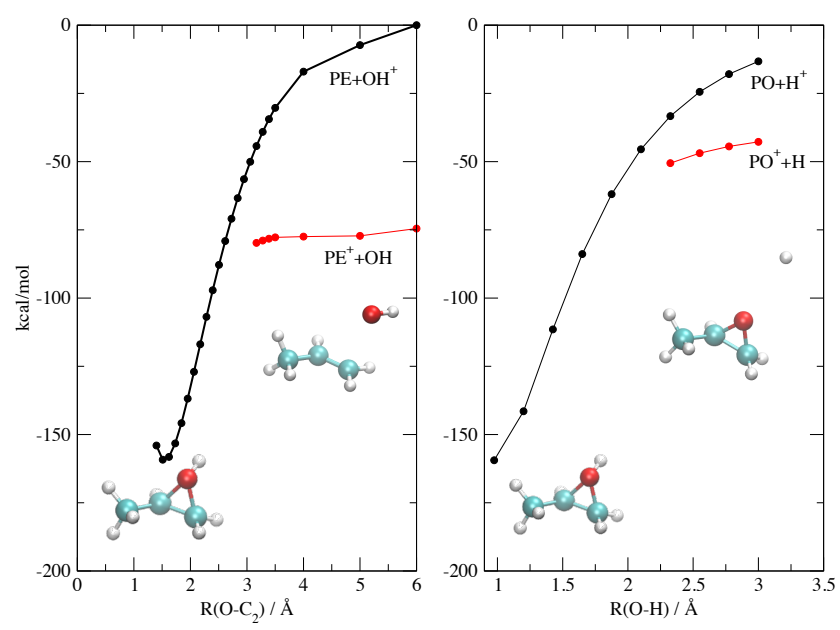

Fig. $6 \mathrm{PE}+\mathrm{OH}^{+}$reaction scan along the $\mathrm{C}-\mathrm{O}$ coordinate on the left (entrance channel) and along the $\mathrm{O}-\mathrm{H}$ coordinate on the right (exit channel). The singlet diradical state energies corresponding to the homolytic cleavage of the bonds are reported in red. The zero has been set to the last point of the entrance channel PES. PBEh-3c calculations are shown.

We point out that, although the reaction processes are barrierless, the collision between $\mathrm{PE}$ and $\mathrm{OH}^{+}$remains unlikely to provide an efficient route to $\mathrm{PO}$ formation because of the presence of a non reactive, low energy charge-exchange product $\left(\mathrm{PE}^{+}+\mathrm{OH}\right)$. In addition, even if $\mathrm{PO}^{+}$is produced, it is necessary a fur- 
ther electron capture process, since the energetically favored product of a reactive $\mathrm{PE}+\mathrm{OH}^{+}$collision is $\mathrm{PO}^{+}$and not neutral PO.

In addition, we have to remark that the ground state electronic configuration of $\mathrm{OH}^{+}$is a ${ }^{3} \Sigma$ (that cannot associate or react directly with PE, unless a very unlikely inter-system crossing takes place) therefore the likelihood of this process depends also on the abundance of ${ }^{1} \Delta$ molecule.

\subsubsection{The $\mathrm{PE}+\mathrm{HO}_{2}^{+}\left({ }^{1} A\right)$ reaction.}

The discussion of this reaction is substantially similar to what we have already said for $\mathrm{PE}+\mathrm{OH}^{+}$. The main differences can be easily grasped by inspection of the right panel of Figure 5. The exit channel that produces directly neutral PO is highly endothermic. The only useful outcome of this reaction for producing PO is in the possibility of forming its ionized precursor $\mathrm{PO}^{+}$that, then, has to be neutralized by electron capture. From our calculations, and contrarily to what we had found for the reaction with $\mathrm{OH}^{+}$, it turns out that the final energy of the reactive $\mathrm{PO}^{+}+\mathrm{OH}$ channel is lower than the non-reactive charge exchange one that leads to $\mathrm{PE}^{+}+\mathrm{OOH}$. Therefore the collision with $\mathrm{OOH}^{+}$can represent an actual viable route to the formation of $\mathrm{PO}^{+}$.
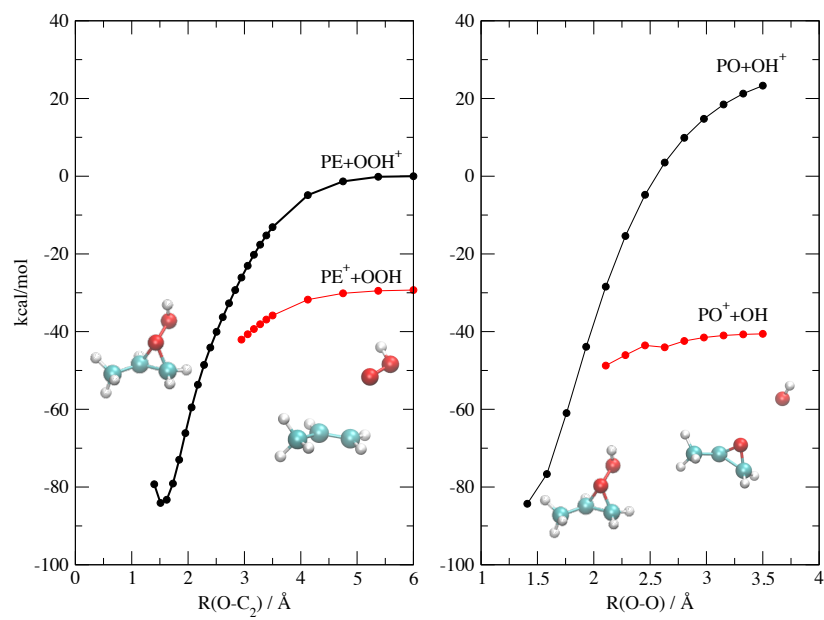

Fig. $7 \mathrm{PE}+\mathrm{OOH}^{+}$reaction scan along the $\mathrm{C}-\mathrm{O}$ coordinate on the left (entrance channel) and along the $\mathrm{O}-\mathrm{O}$ coordinate on the right (exit channel). The singlet diradical state energies corresponding to the homolytic cleavage of the bonds is reported in red. The zero has been set to the last point of the computed entrance channel PES. PBEh-3c calculations are shown.

\section{Conclusions}

In the present work, we have investigated by means of quantum chemistry calculations the possibility of forming propylene oxide (PO) from propylene (PE) in the 
gas phase. In particular, conditions close to the astrophysical ones are discussed: extreme low temperature and density. Bimolecular radical and ionic process have been considered and, as expected, the latter ones are more likely to occurr, in terms of both formation energies and kinetic barriers. Among the bimolecular radical reactions, the collision of $\mathrm{PE}$ with $\mathrm{HO}_{2}$, might represent a possible route of formation once we assume that there exists sufficient UV irradiation to trigger the reaction that proceeds only on an excited state PES. Radiative association processes have also been considered. They are strongly exothermic and barrierless, thereby representing a possible formation route of $\mathrm{PO}$, but competition with unimolecular fragmentation (dominant at low densities) is an important limiting factor for the viability of such processes. The presence of a sufficiently dense environment which removes the excess energy can promote such reactions.

Ion-molecule reactions represent the most likely formation routes of PO in the ISM (at least in a pure gas-phase chemistry). In particular, we have found that the $\mathrm{PE}+\mathrm{HO}_{2}^{+}$collision, which leads directly to the formation of $\mathrm{PO}^{+}$represents an important pathway to $\mathrm{PO}$ once an ensuing recombination with an electron (electron capture or transfer from another species) occurs. The $\mathrm{PE}+\mathrm{OH}^{+}$channel has also been analyzed and turned out to be able to form directly both $\mathrm{PO}^{+}$and PO with barrierless processes, but a competitive charge exchange route leading to $\mathrm{PE}^{+}$and $\mathrm{OH}$ turned out to be thermodynamically favored. Furthermore, it is necessary that $\mathrm{OH}^{+}$be in the high energy ${ }^{1} \Delta$ electronic configuration instead of the more stable ${ }^{3} \Sigma$ one.

Concluding, from this study we have suggested some bi-molecular reactions which can be at the origin of the observation of propylene oxyde in the interstellar medium. Nicely, computationally cheap methods like B3LYP and PBEh-3c provide a good energetic description and thus they could be used in deeper studies using reaction dynamics and/or considering an environment (like a surface) explicitly.

Acknowledgements We thank ANR DynBioReact (Grant No. ANR-14-CE06-0029-01) and CNRS program INFINITI (project ASTROCOL) for support. EB thankfully acknowledges CINECA for its support through computational grant IscrC-COMPAA-2 and "La Sapienza" for its financial support through grant RM11715C7C86B2BE.

\section{References}

1. N. Marcelino, J. Cernicharo, M. Agúndez, E. Roueff, M. Gerin, J. Martín-Pintado, R. Mauersberger, C. Thum, Astrophys. J. 665, L127 (2007)

2. R. Rubin, G. Swenson Jr, R. Benson, H. Tigelaar, W. Flygare, Astrophys. J. 169, L39 (1971)

3. L.E. Snyder, D. Buhl, Astrophys. J. 177, 619 (1972)

4. S. Brünken, A. Belloche, S. Martín, L. Verheyen, K.M. Menten, Astron. Astrophys. 516, A109 (2010)

5. V.M. Rivilla, J. Martín-Pintado, I. Jiménez-Serra, S. Zeng, S. Martín, J. ArmijosAbendaño, M.A. Requena-Torres, R. Aladro, D. Riquelme, Mon. Not. R. Astron. Soc. 483(1), L114 (2018)

6. S. Zeng, D. Quénard, I. Jiménez-Serra, J. Martín-Pintado, V.M. Rivilla, L. Testi, R. Martín-Doménech, Mon. Not. R. Astron. Soc. 484(1), L43 (2019)

7. B.A. McGuire, P.B. Carroll, R.A. Loomis, I.A. Finneran, P.R. Jewell, A.J. Remijan, G.A. Blake, Science 352, 1449 (2016)

8. P. de Marcellus, C. Meinert, I. Myrgorodska, L. Nahon, T. Buhse, L.L.S. d'Hendecourt, U.J. Meierhenrich, PNAS 112, 965 (2015) 
9. A. Forstel, P. Maksytenko, B.M. Jones, B.J. Sun, A.H.H. Chang, R.I. Kaiser, Chem. Commun. 52, 741 (2016)

10. J.A. Elsila, J.P. Dworkin, M.P. Bernstein, M.P. Martin, S.A. Sandford, Astrophys. J. 660, $911(2007)$

11. P.D. Holtom, C.J. Bennet, Y. Osamura, N.J. Mason, R.I. Kaiser, Astrophys. J. 626, 940 (2005)

12. J.B. Bergner, K.I. Öberg, M. Rajappan, Astrophys. J. 845(1), 29 (2017)

13. W.D. Geppert, M. Larsson, Chem. Rev. 113, 8872 (2013)

14. M. Larsson, W.D. Geppert, G. Nyman, Rep. Prog. Phys. 75, 066901 (2012)

15. S. Petrie, D.K. Bohme, Mass Spec. Rev. 26, 258 (2007)

16. E. Roueff, in Gas-Phase Chemistry in Space, 2514-3433 (IOP Publishing, 2019), pp. 8-1 to $8-36$

17. K.M. Ferrière, Rev. Mod. Phys. 73, 1031 (2001)

18. A.I. Vasyunin, E. Herbst, Astrophys. J. 769(1), 34 (2013)

19. E. Herbst, R.C. Dunbar, Mon. Not. R. Astr. Soc. 253, 341 (1991)

20. Siro Brigiano, F., Y. Jeanvoine, A. Largo, R. Spezia, Astron. Astrophys. 610, A26 (2018)

21. A. Pérez-Villa, F. Pietrucci, A.M. Saitta, Physics of Life Reviews (2018)

22. P. Redondo, C. Barrientos, A. Largo, Astrophys. J. 780(2), 181 (2014)

23. P. Redondo, C. Barrientos, A. Largo, Astrophys. J. 793(1), 32 (2014)

24. V. Barone, C. Latouche, D. Skouteris, F. Vazart, N. Balucani, N. Ceccarelli, B. Lefloch, Mon. Not. R. Astron. Soc. Lett. 453, L31 (2015)

25. A.M. Saitta, F. Saija, Proc. Nat. Acad. Sci. USA 111(38), 13768 (2014)

26. A. Rimola, V. Taquet, P. Ugliengo, N. Balucani, C. Ceccarelli, A \& A 572, A70 (2014)

27. L. Chen, D.E. Woon, J. Phys. Chem. A 115, 5166 (2011)

28. J. Enrique-Romero, A. Rimola, C. Ceccarelli, N. Balucani, Mon. Not. R. Astron. Soc. Lett. 459(1), L6 (2016)

29. D. Skouteris, N. Balucani, C. Ceccarelli, F. Vazart, C. Puzzarini, V. Barone, C. Codella, B. Lefloch, Astrophys. J. 854(2), 135 (2018)

30. J.L. Neill, A.L. Steber, M.T. Muckle, D.P. Zaleski, V. Lattanzi, S. Spezzano, M.C. McCarthy, A.J. Remijan, D.N. Friedel, S.L. Widicus Weaver, B.H. Pate, J. Phys. Chem. A $\mathbf{1 1 5}(24), 6472(2011)$

31. G. Danger, A. Rimola, N.A. Mrad, F. Duvernay, G. Roussin, T. P., T. Chiavassa, Phys. Chem. Chem. Phys. 16, 3360 (2014)

32. J.L. Snow, G. Orlova, V. Blagojevic, D.K. Bohme, J. Am. Chem. Soc. 129(32), 9910 (2007)

33. C. Barrientos, P. Redondo, L. Largo, V.M. Rayón, A. Largo, Astrophys. J. 748(2), 99 (2012)

34. R. Spezia, Y. Jeanvoine, W.L. Hase, K. Song, A. Largo, Astrophys. J. 826, 107 (2016)

35. Y. Jeanvoine, A. Largo, W.L. Hase, R. Spezia, J. Phys. Chem. A 122(3), 869 (2018)

36. Y. Jeanvoine, R. Spezia, Theor. Chem. Acc. 138, 1 (2019)

37. A.E. Glassgold, W.D. Langer, Astrophys. J. 206, 85 (1976)

38. D. Hollenbach, M.J. Kaufman, E.A. Bergin, G.J. Melnick, Astrophys. J. 690, 1497 (2009)

39. Wiesemeyer, H., Güsten, R., Heyminck, S., Hübers, H. W., Menten, K. M., Neufeld, D. A., Richter, H., Simon, R., Stutzki, J., Winkel, B., Wyrowski, F., A\&A 585, A76 (2016)

40. Wyrowski, F., Menten, K. M., Güsten, R., Belloche, A., A\&A 518, A26 (2010)

41. Parise, B., Bergman, P., Du, F., A\&A 541, L11 (2012)

42. Widicus Weaver, S. L., D.E. Woon, B. Ruscic, McCall, B.J., Astrophys. J. 697(1), 601 (2009)

43. M.R. Cunningham, P.A. Jones, P.D. Godfrey, D.M. Cragg, I. Bains, M.G. Burton, P. Calisse, N.H.M. Crighton, S.J. Curran, T.M. Davis, J.T. Dempsey, B. Fulton, M.G. Hidas, T. Hill, L. Kedziora-Chudczer, V. Minier, M.B. Pracy, C. Purcell, J. Shobbrook, T. Travouillon, Mon. Not. R. Astron. Soc. 376, 1201 (2007)

44. M.J. Frisch, G.W. Trucks, H.B. Schlegel, G.E. Scuseria, M.A. Robb, J.R. Cheeseman, G. Scalmani, V. Barone, G.A. Petersson, H. Nakatsuji, X. Li, M. Caricato, A.V. Marenich, J. Bloino, B.G. Janesko, R. Gomperts, B. Mennucci, H.P. Hratchian, J.V. Ortiz, A.F. Izmaylov, J.L. Sonnenberg, D. Williams-Young, F. Ding, F. Lipparini, F. Egidi, J. Goings, B. Peng, A. Petrone, T. Henderson, D. Ranasinghe, V.G. Zakrzewski, J. Gao, N. Rega, G. Zheng, W. Liang, M. Hada, M. Ehara, K. Toyota, R. Fukuda, J. Hasegawa, M. Ishida, T. Nakajima, Y. Honda, O. Kitao, H. Nakai, T. Vreven, K. Throssell, J.A. Montgomery, Jr., J.E. Peralta, F. Ogliaro, M.J. Bearpark, J.J. Heyd, E.N. Brothers, K.N. Kudin, V.N. Staroverov, T.A. Keith, R. Kobayashi, J. Normand, K. Raghavachari, A.P. Rendell, J.C. 
Burant, S.S. Iyengar, J. Tomasi, M. Cossi, J.M. Millam, M. Klene, C. Adamo, R. Cammi, J.W. Ochterski, R.L. Martin, K. Morokuma, O. Farkas, J.B. Foresman, D.J. Fox. Gaussian 16 Revision B.01 (2016)

45. F. Neese, Wiley Interdisciplinary Reviews: Computational Molecular Science 8(1), e1327 (2018)

46. P. Stephens, F. Devlin, C. Chabalowski, M. Frisch, J. Phys. Chem. 98, 11623 (1994)

47. T.H. Dunning Jr., J. Chem. Phys. 90, 1007 (1989)

48. T. Schwabe, S. Grimme, Phys. Chem. Chem. Phys. 9, 3397 (2007)

49. R. Kendall, T. Dunning Jr., R.J. Harrison, J. Chem. Phys 96, 6796 (1992)

50. M. Head-Gordon, J.A. Pople, M.J. Frisch, Chem. Phys. Lett. 153, 503 (1988)

51. S. Grimme, J.G. Brandenburg, C. Bannwarth, A. Hansen, The Journal of Chemical Physics 143(5), 054107 (2015)

52. G.D. Purvis III, R.J. Bartlett, J. Chem. Phys. 76, 1910 (1982)

53. M. Lattelais, F. Pauzat, Y. Ellinger, C. Ceccarelli, Astrophys. J. 696, L133 (2009)

54. M. Lattelais, F. Pauzat, Y. Ellinger, C. Ceccarelli, Astron. Astrophys. 519, A30 (2010)

55. M.S. Stark, J. Am. Chem. Soc. 122, 4162 (2000)

56. M.S. Stark, J. Phys. Chem. 101, 8296 (1997)

57. L. Barnes, S. Abdul-Al, A.R. Allouche, J. Phys. Chem. A 118, 11033 (2014)

58. E. Herbst, R.C. Dunbar, Mon. Not. R. Astr. Soc. 253, 341 (1991)

59. I. Savic, S. Schlemmer, D. Gerlich, Astrophys. J. 621, 1163 (2005)

60. S.G. Lias, in NIST Chemistry WebBook, NIST Standard Reference Database (National Institute of Standards and Technology, 2019)

61. J. Berkowitz, G. Ellison, D. Gutman, J. Phys. Chem. 98, 2744 (1994)

62. P. Thaddeus, M. Guelin, R.A. Linke, Astrophys. J. Lett. 246, L41 (1981) 